\title{
Heated Air Adiabatic Saturation Psychrometer
}

\author{
Lewis Greenspan \\ Institute for Basic Standards, National Bureau of Standards, Washington, D.C. 20234
}

(December 29, 1970)

\begin{abstract}
A portable self-contained heated-air adiabatic saturation psychrometer intended as a field and laboratory instrument has been developed and constructed. The instrument measures the humidity of air in the range from 0 to 50 grams of water vapor per kilogram of dry air over an ambient temperature range of -5 to $40{ }^{\circ} \mathrm{C}$. It samples a test gas at the rate of 4 liters per minute.

The psychrometer was compared with the NBS pressure humidity generator over the mixing ratio range of 2.5 to 19 grams of water per kilogram of dry air (equivalent to a dew-point range of -5.4 to $24{ }^{\circ} \mathrm{C}$ at atmospheric pressure). The mixing ratio indicated by the psychrometer was higher than that produced by the generator by $0.025 \mathrm{~g} / \mathrm{kg}+0.24$ percent of the reading with a standard deviation of $0.024 \mathrm{~g} / \mathrm{kg}$; that is, it was higher by 1.24 percent to 0.37 percent of the reading as the measured mixing ratio increased from 2.5 to $19 \mathrm{~g} / \mathrm{kg}$. In equivalent terms of dew point, the psychrometer reading was higher by $0.16 \mathrm{deg} C$ to $0.06 \mathrm{deg} \mathrm{C}$ as the measured dew point increased from -5.4 to $24.0^{\circ} \mathrm{C}$. The results are approximately those which would be expected based on an analysis of estimated errors in individual measurements.
\end{abstract}

Key words: Adiabatic saturation; dew point temperature; humidity; hygrometer; mixing ratio; moist gas; psychrometer; vapor pressure.

\section{Introduction}

Although the psychrometer is one of the oldest and most common instruments used to measure the humidity of air, no theory adequately predicts its performance. Empirical and semiempirical formulas exist which describe, under limited conditions, the performance of psychrometers of particular dimensions and configurations.

In 1967, we developed and constructed a laboratory model of an adiabatic saturation psychrometer $[1]^{1}$ the performance of which is specified by means of an equation. This instrument differed from other psychrometers in that it was designed to utilize a steady-flow adiabatic isobaric saturation process, whereas other psychrometers, even under steady-state conditions, are an open system undergoing a nonequilibrium process which cannot be described completely by classical thermodynamics. It was tested with various fluids and gases under conditions of zero vapor content. Because the results agreed with an equation derived from classical thermodynamics to within the limits of the experimental uncertainties associated with the conducted tests, it was concluded that the equation did indeed predict the behavior of this adiabatic saturation psychrometer. This was particularly significant in the tests with vapor-gas systems other than water-air where other psychrometers give results which differ markedly from those derived from the postulates of classical thermodynamics.

The adiabatic saturation psychrometer has been developed further into a portable and self-contained instrument, intended for both laboratory and field use. In order to permit its employment at low ambient dry-bulb tempera-

1 Figures in brackets indicate the literature references at the $\epsilon$ nd of this paper. tures of meteorological interest without freezing of the wet-bulb water supply and wicking, provision was made for heating the test air to a fixed elevated temperature.

It appeared to us that the heated-air adiabatic saturation psychrometer could be used to investigate more fully the validity of our earlier conclusion that the instrument performed in accordance with the derived equation. It had been suggested that because the original tests had been made only under conditions of zero vapor content, the equation had been validated only under this unique condition and that the use of the relationship at other humidities could not be accepted with complete certainty.

We believed that the condition of zero vapor content was a unique condition only in that it represented the most severe condition under which to test the behavior of a psychrometer, and that the instrument would behave in accordance with the derived equation at all vapor contents. The availability in our laboratory of a highly accurate humidity generator [2] made it feasible for us to perform an extensive series of tests over a wide range of humidities.

The general design and operational features, as well as the test results, of the heated-air adiabatic saturation psychrometer are the subjects of this paper.

\section{Theory}

When a quantity of liquid or solid water at pressure $P$ and temperature $T_{w}$ is evaporated into a vapor-gas mixture at pressure $P$, temperature $T$ and mixing ratio $r$ to bring the gas adiabatically to saturation at pressure $P$, temperature $T_{w}$ and mixing ratio $r_{w}$, the sum of the enthalpies of the various phases are conserved. Thus the 
initial and final enthalpies are equal, leading to the following equation:

$$
h(P, T, r)+\left(r_{w}-r\right) h_{w}^{\prime}\left(P, T_{w}\right)=h\left(P, T_{w}, r_{w}\right)
$$

where

$h(P, T, r)=$ the enthalpy per gram of dry (vapor-free) gas of the initial vapor-gas mixture at pressure $P$, temperature $T$ and mixing ratio $r$;

$h\left(P, T_{w}, r_{w}\right)=$ the enthalpy per gram of dry gas of the final vapor-gas mixture at pressure $P$, temperature $T_{w}$ and mixing ratio $r_{w}$;

$h^{\prime}{ }_{w}\left(P, T_{w}\right)=$ the enthalpy per gram of liquid or solid water at pressure $P$ and temperature $T_{w}$.

$r=$ the mixing ratio of the initial vapor-gas mixture in grams of vapor per gram of associated dry gas.

$r_{w}=$ the saturation mixing ratio of the final vapor gas mixture in grams of vapor per gram of associated dry gas.

Since $r_{w}$ is a function of only $T_{w}$ and $P, r$ may be determined by means of (1) from a knowledge of $P, T$, $T_{w}$ and other available data for the gas, vapor and liquid or solid involved.

We have built an instrument which approaches a steadystate adiabatic saturation flow process and, to which eq (l) may be applied. It consists of a well insulated enclosure where a gas is saturated and liquid at exit temperature, sufficient for evaporation, is provided, as well as means for measuring entrance and exit temperatures and pressure. In accordance with the terminology uşually used in psychrometry, the entrance and exit temperature also will be called the dry-bulb and wet-bulb temperatures in this paper. In a conventional psychrometer, the wet-bulb temperature is the temperature of a wetted thermometer whereas in this psychrometer, the wet-bulb temperature is the temperature of the exit gas.

Equation (1) describes an ideal system which the instrument is not. Among the deviations from ideality are the following: (1) The instrument is not isobaric but has a pressure drop of the order of $1 / 2$ percent of the total pressure; (2) The velocity of gas changes in the instrument due to its change in pressure and temperature as well as changes in cross-sectional area and the addition of vapor to the gas; (3) The enclosure is not a perfect adiabatic enclosure; (4) The liquid may not enter the instrument at precisely the gas exit temperature; (5) The gas may not be precisely saturated at exit. No attempt was made to evaluate these various effects individually in this instrument. An analysis of the overall performance of the instrument was utilized to determine the overall effect of these deviations from ideality. In addition, equation (1) refers only to an equilibrium condition and is not applicable when inlet temperature or humidity are changing or shortly after a change.

The instrument is modified in one important respect: the entrance gas is heated. This does not affect eq (1) since the entrance temperature is measured subsequent to the heating and it is this elevated temperature which enters into the computations. The range of the instrument is increased by this heating since it ensures exit temperatures above freezing regardless of the conditions of temperature and humidity of the test gas prior to heating.

\section{Description}

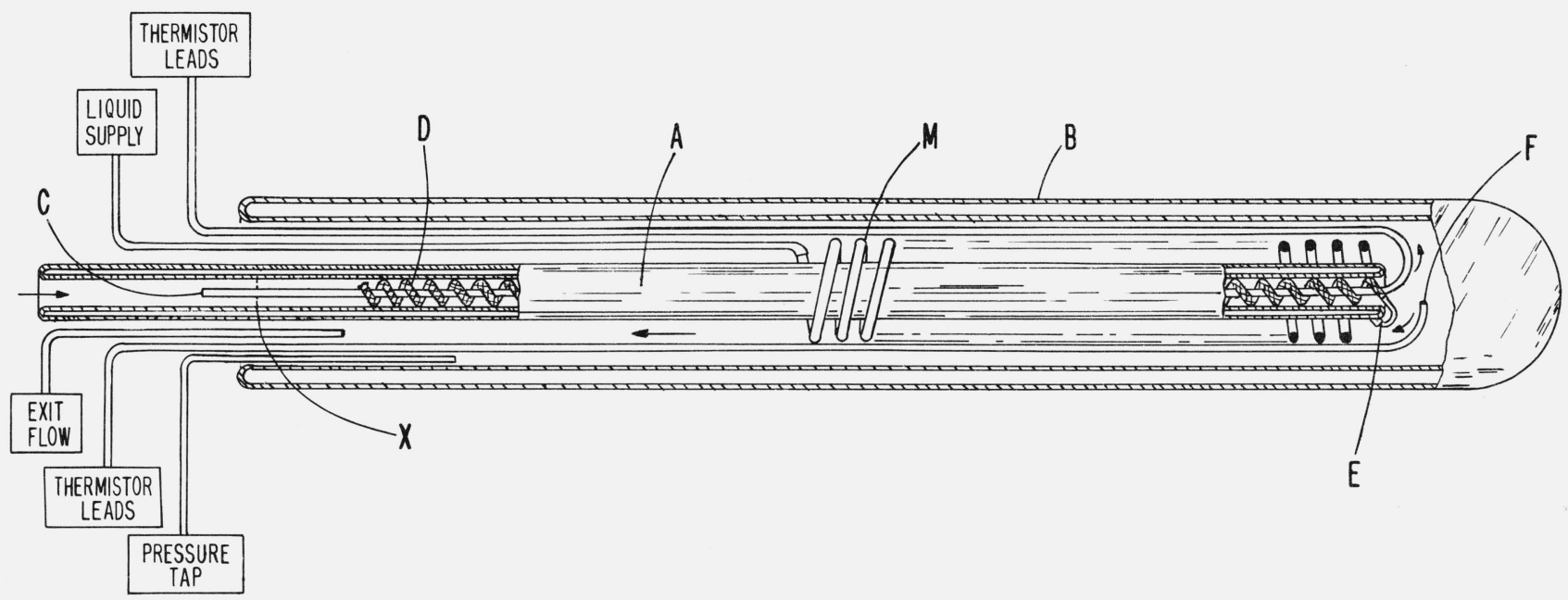

Figure 1. Main psychrometer components. A. Vacuum-jacketed glass saturator tube; B. glass Dewar flask; C. dry-bulb thermistor; D. glass fiber wicking; E. liquid feed tube; F. wet-bulb thermistor

\subsection{General Features}

The instrument is shown in figures $1,2,3,4$, and 5 . Figure 1 is a drawing of the main psychrometer components without regard to actual dimensions. The instrument consists of a vacuum-jacketed glass saturator tube A, which is surrounded by a glass Dewar flask B. Thermistor $\mathrm{C}$, which is positioned within the saturator tube on its axis by means of locator disk $\mathrm{X}$, measures the temperature of the test gas as it enters the saturator tube. Glass fiber wicking $\mathrm{D}$, maintained in a moist condition by means of water fed through feed-tube E, provides the means for saturating the test gas. Thermistor F, located beyond the outlet end of the saturator tube, measures the exit gas temperature. Heat exchanger M, a helix of stainless steel 
capillary tubing surrounding the saturator tube, controls the temperature of the water moistening the wicking $\mathrm{D}$. Exiting from the Dewar flask are the thermistor leads, a pressure tap, a plastic water-fed tube (through which water enters from a liquid supply) and a gas-flow exit tube.

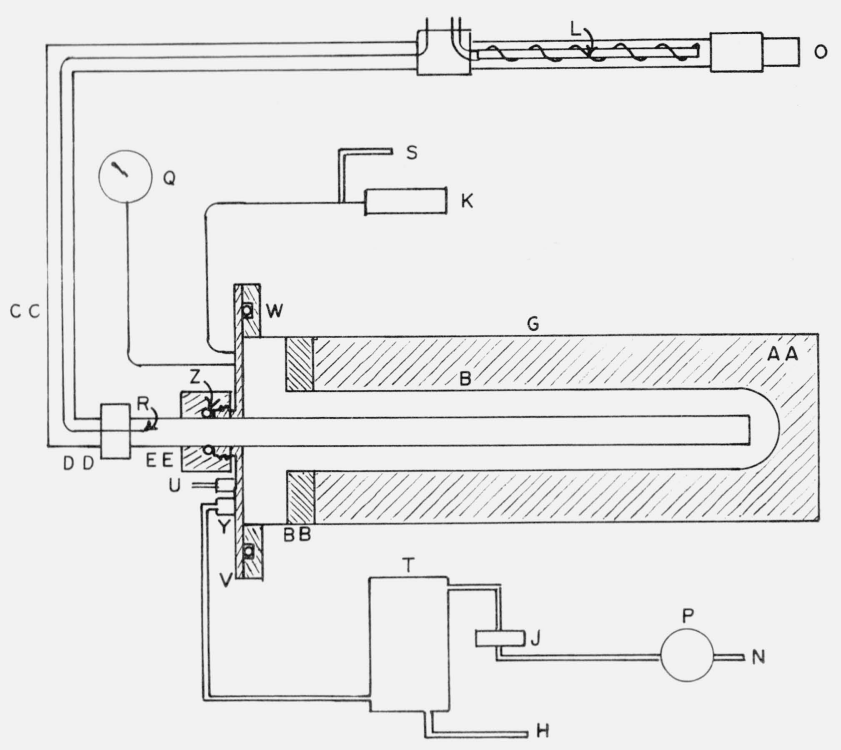

FigUre 2. Schematic diagram of auxiliary components.

B. Glass Dewar flask; G. brass cylinder; H. trap drain; J. critical nozzle flow controller; K. syringe pump; L. nickel-chrome heater coil; N. flow exit; O. flow entrance; P. vacuum pump; Q. differential pressure gage; R. control thermistor; S. liquid filler tube; T. liquid trap; U. thermistor leads; V. cylinder cap; W. "O' ring; Y. compression seal; Z. "O" ring; AA polystyrene foam packing; BB. rubber stopper; CC. insulated polytetrafluoroethylene tubing; DD, saturator tube connector; EE. cap seal assembly; FF. pressure signal tubing; HH. polytetrafluoroethylene liquid flow tubing.

Figure 2 is a schematic representation of all hydraulic and pneumatic components not shown in figure 1 . A brass cylinder $\mathrm{G}$ surrounds the Dewar flask B shown in figure 1. Flask $B$ is held rigidly in place on the axis of $\mathrm{G}$ by means of polystyrene foam packing, AA. Cap V is sealed to saturator tube A by means of "O" ring $\mathrm{Z}$ within assembly EE, and to cylinder $\mathrm{G}$ by means of "O" ring W. In addition to providing the means for sealing, cap $\mathrm{V}$ supports and locates saturator tube A coaxially within Dewar flask B. Insulated polytetrafluoroethylene tubing CC connects to the saturator tube. The thermistor leads, pressure tap, plastic water-feed tube and gas flow exit tube pass through compression seals in cap V. Test gas enters the instrument at $\mathrm{O}$, is heated by the nickel-chrome heater coil L, flows through tubing CC and enters the saturator tube. After passing over the moist wicking it leaves the psychrometric section at $\mathrm{Y}$ and passes through trap T, where entrained water is separated from the gas stream. The trap is drained through tube $H$. The gas then passes through the critical nozzle flow controller J and on through vacuum pump $P$, and exits at N. Differential pressure gage $Q$ measures the pressure difference between flask B and atmospheric pressure. Syringe pump $\mathrm{K}$ forces liquid into the instrument at a constant rate of flow. The syringe is refilled through tube S. The temperature of the air entering the saturator tube is sensed by thermistor R, which in conjunction with a proportional heat controller (not shown) controls the voltage supplied to heater L, thereby regulating the temperature of the air entering the saturator tube to $413 / 4{ }^{\circ} \mathrm{C}$. $\pm 3 / 4{ }^{\circ} \mathrm{C}$.

Figure 3 is a circuit diagram of the two Wheatstone bridges, power supply and galvanometer circuit. The Wheatstone bridges and galvanometer measure the entrance (dry-bulb) and exit (wet-bulb) thermistor resistances. In addition, there are two temperature control circuits (not shown) operating from mechanical thermostats. One of the temperature control circuits regulates the air temperature surrounding the Wheatstone bridge and the other prevents the section of the instrument which contains water from falling to freezing temperature.

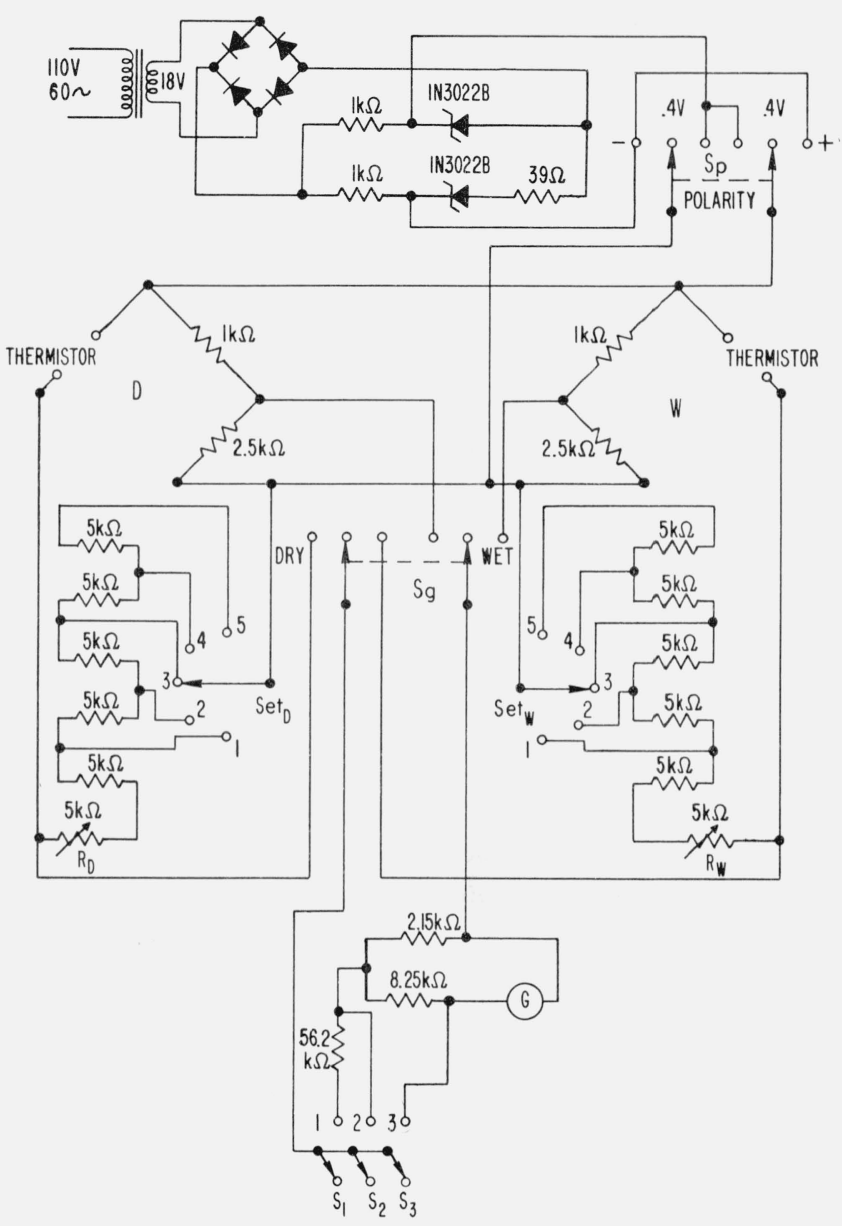

Figure 3. Temperature measurement circuit.

D. Dry-bulb temperature bridge; W. wet-bulb temperature bridge; G. galvanometer; $R_{D}$. dry-bulb heliopot; $R_{W}$. wet-bulb heliopot; Set . dry-bulb step switch; Setw. wet-bulb step switch; Sp. polarity reversing switch; $\mathbf{S}_{\mathbf{g}}$. wet-bulb or dry-bulb selector switch; $\mathrm{S}_{\mathbf{1}}$, low sensitivity galvometer switch; $\mathrm{S}_{2}$. medium sensitivity galvanometer switch; $\mathrm{S}_{3}$. high sensitivity ga $a_{4}$ vanometer switch.

Figure 4 is a top view photograph of the instrument assembled and ready for operation. The instrument is 23-in long, 16-in wide and 13-in high, and weighs $771 / 2$ pounds.

Figure 5 is a photograph of the section where the water is drained and the syringe refilled, taken with the side panel removed and lying in front of the instrument. 


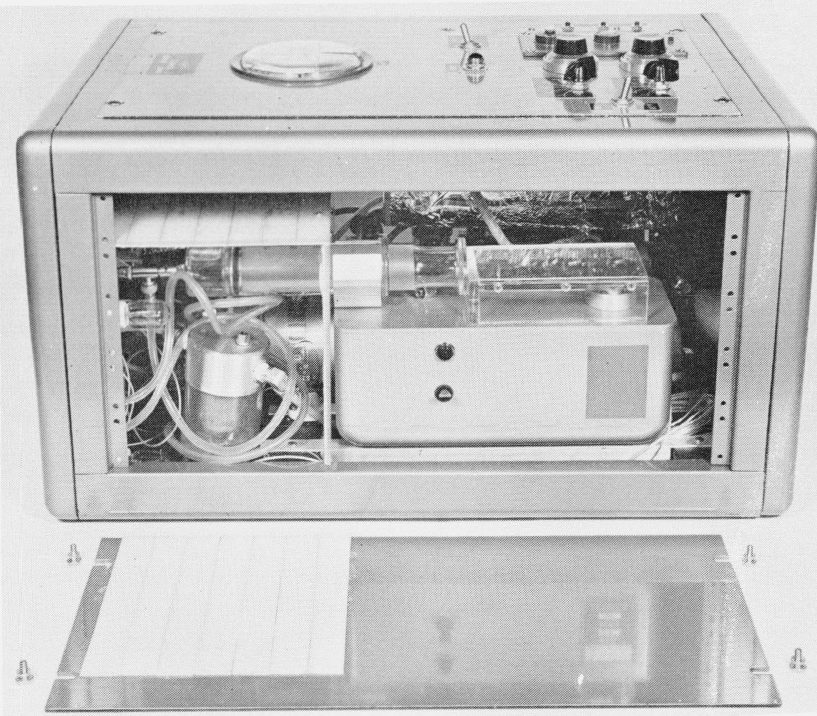

Figure 4. Psychrometer top view.

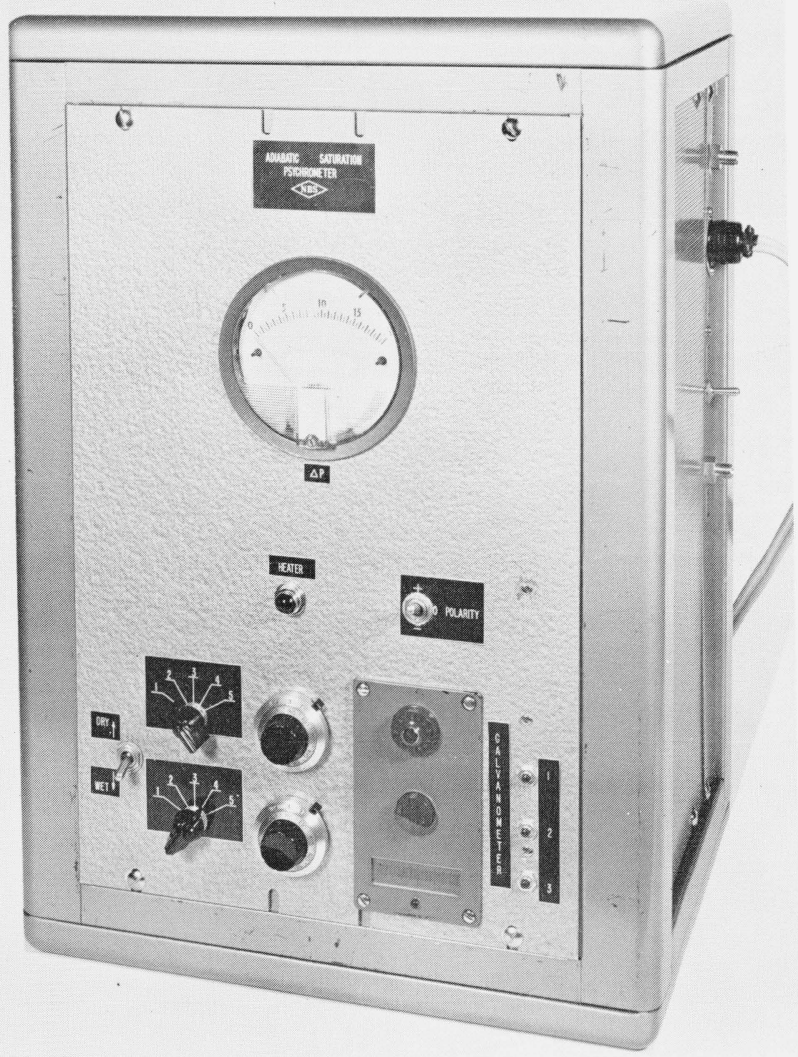

Figure 5. Psychrometer side view.

\subsection{Saturator Assembly}

The saturator tube is a straight double-walled glass tube, 18-in long, with an i.d. of $1 / 4$ in and an o.d. of $5 \% 8$ in. The space between the walls is evacuated and the glass surface within this space is silvered.
The saturating element is a helix with a fiber glass surface. It was made by covering $7 \mathrm{ft}$ of polytetrafluoroethylene tubing, having an i.d. of about 0.022 in and an o.d. from $0.042-0.050$ in, with number 22 -gage fiber glass spaghetti. The fiber glass spaghetti extends beyond the upstream end of the polytetrafluoroethylene tubing and is tied off with linen thread. The tubing was wound into a helix of $1 / 4$-in o.d. and placed in boiling water for $1 \mathrm{hr}$. This had the effect of cleaning the fiber glass spaghetti and setting the polytetrafluoroethylene into a quasipermanent helical shape.

\subsection{Water Heat-Exchanger}

Eight feet of stainless steel tubing with an o.d. of 0.0355 in and an i.d. of 0.023 in, wound into a $3 / 4$-in helix, serves as the water heat-exchanger. This exchanger surrounds the saturator tube and is joined at one end to the polytetrafluoroethylene tubing of the saturating element and at the other end to a polytetrafluoroethylene tube which is fed through a pressure seal in cap $V$ to the water-feed pump. At the normally used water flow-rate of $10 \mathrm{~cm}^{3} / \mathrm{h}$, there is a 4 min supply of water within the heat exchanger.

The heat exchanger is surrounded by a Dewar flask with an i.d. of $7 / 8$ in. and a straight section of 14 in. This flask reduces heat losses from the region around the heat exchanger.

\subsection{Outer Case}

In order to protect the glass elements and to seal the saturator tube so that the test gas flows as desired, a brass cylinder 17 in long, with an o.d. of 3 in and a wall thickness of $1 / 8$ in, closed at one end, surrounds the Dewar flask. The space between the flask and the brass cylinder is filled with foamed polystyrene and a rubber stopper, permanently positioning the flask within the cylinder along its axis. At the open end of the cylinder is a flange which mates with cap $V$ and seals to the cap by means of a 3-in i.d. "O" ring. The cap is held to the cylinder with screws.

The cap has four openings within it. At its center is an opening through which the saturator tube protrudes. By means of an "O" ring seal, the cap is sealed to the outer surface of the saturator tube and positions this tube within the Dewar flask.

Two of the other openings in the cap are polytetrafluoroethylene packing-gland compression seals. One of the seals holds the pressure tap and water-feed tube, and the other serves as a pass-through for the two thermistor leads. The remaining opening in the cap serves as a flow exit for the test gas.

\subsection{Air Heater}

The test gas heater $\mathrm{L}$ is formed by winding $25 \mathrm{ft}$ of bare nickel-chrome wire on a 1 -ft long, $1 / 4$-in diam, polytetrafluoroethylene rod. The rod has a few longitudinal grooves for the lead wire and to expose more of the wire to the air flow. The heater is contained within a $3 / 8$-in polytetrafluoroethylene tube which is surrounded with rubber foam insulation. The small diameter bare wire has a low thermal lag. 


\subsection{Temperature Regulator}

The inlet test gas temperature is controlled by a proportional electronic temperature controller. The sensor $\mathrm{R}$ which activates the controller is placed in the test gas flow stream just at the inlet to the saturator tube.

\subsection{Temperature Measuring Circuit}

The temperature measuring circuit is shown in figure 3. It consists of two separate Wheatstone bridges $D$ and $\mathrm{W}$, each connected to a thermistor encased in polyethylene tubing. One of the thermistors is held in place at the entrance end of the saturator tube by means of a polytetrafluoroethylene disk containing many holes, while the other thermistor is secured along the axis at the exit of the saturator tube by means of a small diameter wire. The bridge circuit is powered by $0.4 \mathrm{~V}$ from the power supply and the voltage is continuously supplied to each bridge circuit, including thermistor, whenever the psychrometer is in operation, in order to maintain constant self-heating of thermistors. A selector switch $\mathrm{Sg}$ allows the reflecting galvanometer $\mathrm{G}$ to be connected to either of the bridge circuits as desired. A switch Sp provides for a reversal of voltage polarity to the bridges in order to obtain an electrical zero in the balancing of the bridges. The polarity switch also removes the voltage from the bridge circuits whenever it is placed in its center position. There are three buttons, S1, S2, S3, which connect the galvanometer into the circuit, each having resistance circuits which provide for three different galvanometer sensitivities. The power supply is supplied with $18 \mathrm{~V}$ from a transformer.

The bridge circuits, power supply and galvanometer are contained in a separate enclosure within the instrument cabinet which is temperature regulated. Temperature in the enclosure is maintained by means of a $44-\mathrm{W}$ heater and a miniature thermoswitch preset to $40{ }^{\circ} \mathrm{C}$. A miniature blower within the enclosure operates continuously, and a panel light on the top of the psychrometer indicates whenever the heater is on.

\subsection{Flow System}

Flow is drawn through the psychrometer by means of a moisture-resistant vacuum pump, $P$. Upstream of the vacuum pump is a nozzle assembly $\mathbf{J}$ which limits the flow to approximately four ambient liters per/minute. Upstream of the nozzle assembly is a water trap $\mathrm{T}$ which separates liquid from the exit gas. The level of liquid in the trap is determined visually, and the trap is drained by means of a plastic tube $\mathrm{H}$ connected to the trap.

\subsection{Water-Feed System}

When operating, water is pumped into the psychrometer at the rate of $10 \mathrm{~cm}^{3}$ per hour by means of a syringe pump K. A motor drives the plunger of a $100 \mathrm{~cm}^{3}$ glass syringe. An "O" ring fits into a groove on the piston to provide a leak-free seal in the syringe. Connected to the syringe is a two-way automatic valve which allows for filling of the syringe without disconnecting it or disassembly. A plastic filler tube S remain connected to the twoway valve at one tap. Attached to the other tap of the two-way valve is a hypodermic needle to which, in turn, is connected the tubing $\mathrm{HH}$ that goes through the pressure seal in the cap $V$ of the brass case $G$ to the heat exchanger $\mathrm{M}$ in Dewar flask B.

In the region around the syringe $\mathrm{K}$ and liquid trap $\mathrm{T}$ are located three $15-\mathrm{W}$ miniature light bulbs connected in parallel. These are connected, in turn, through an adjustable liquid-bellows type thermoswitch, directly to the power cord to the instrument, and constitute the freezeprotection circuit.

\subsection{Pressure Measurements}

A plastic tube connects the pressure tap in the psychrometer to a differential pressure gage $Q$, having a range of 0 to 20 -in of water. The gage is mounted at the top of the instrument. The gage pressure, when subtracted from the ambient pressure (independently determined), gives the pressure $P$ in the psychrometer. If the pressure of the test gas is not at atmospheric pressure but is known, another plastic tube can be connected to the reference port of the differential pressure gage Q and connected to the test gas source. The psychrometer pressure $P$ is then the source pressure less the gage pressure.

\subsection{Thermistor Calibration}

It was desirable to have an equation for temperature in terms of bridge switch positions and potentiometer readings. Since the resistance of the thermistors is an exponential function of temperature, a least squares fit to an equation of the following form was made:

$$
T=A+B \ln x+C(\ln x)^{2}{ }^{\circ} \mathrm{C}
$$

where

$$
\begin{aligned}
& x=0.9847 \operatorname{Set}_{D}+0.001 R_{D} \text { for the inlet thermistor } \\
& \text { and } \\
& x=0.9846 \text { Set }_{W}+0.001 R_{W} \text { for the outlet thermistor. }
\end{aligned}
$$

Set ${ }_{D}$ and Set $w$ are indicated switch positions from 1 to 5 and represent nominal bridge resistances of $5,000 \Omega$ per unit. $R_{D}$ and $R_{W}$ are helipot readings from 0 to 1,000 and represent nominal bridge resistances of $5 \Omega$ per unit. The values 0.9847 and 0.9846 are the ratios of the mean of the step resistances to the maximum variable resistance in the corresponding bridge. The bridge has a ratio of 2.5 to 1 and therefore the resistance of the thermistors is approximately 2,000 $x$. The thermistors were simultaneously calibrated at 34 different temperatures against a calibrated platinum resistance thermometer. Two of the calibration points were eliminated from both calibrations and one other from the outlet thermistor calibration for statistical reasons. Fits were then obtained as follows:

$$
\begin{aligned}
& T_{D}=67.09652-32.43244 \ln x+2.109868(\ln x)^{2}{ }^{\circ} \mathrm{C} \\
& T_{W}=61.16210-32.65236 \ln x+2.230575(\ln x)^{2}{ }^{\circ} \mathrm{C} .
\end{aligned}
$$

The residual standard deviation for $T_{D}$ was $0.01{ }^{\circ} \mathrm{C}$ and for $T_{W}$ it was $0.007{ }^{\circ} \mathrm{C}$. 


\section{Calibration}

The psychrometer was operated with a continuous sample of humid air supplied by the NBS pressure humidity generator [3] over a range of mixing ratios from 2.5 to 19 grams of water vapor per kilogram of dry air. The mixing ratio, $r$, obtained by measurements with the psychrometer was calculated by computer on the basis of eq (1). Expressions for the enthalpies of moist air in terms of IT calories per gram of dry air were obtained from the equation given on page 334 of the Smithsonian Meteorological Tables [4] which when inserted into equation (1) yielded the following equation:

$$
\frac{-0.2405095 \Delta \mathrm{T}+0.4408952 r_{w}\left(T_{w}+1354.74\right)}{0.4408952\left(T_{w}+1354.74\right)-h_{\mathrm{w}}^{\prime}}
$$

where

$h^{\prime}{ }_{w}=h^{\prime}{ }_{w}\left(P, T_{\mathrm{w}}\right)$ at atmospheric pressure and was obtained by interpolation from a table given by Goff [5] in terms of BTU/lb. These values were divided by 1.8 to obtain IT calories per gram.

$$
\begin{gathered}
r_{w}=\frac{0.62198 f_{w} e_{w}}{P-f_{w} e_{w}} \text { grams/gram }[6] \\
f_{w}=\exp \left[a\left(T_{w}\right) \times\left(1-\frac{e_{w}}{p}+\beta\left(T_{w}\right) \times\left(\frac{p}{e_{w}}-1\right)\right.\right.
\end{gathered}
$$

dimensionless quantity [5]

$a\left(T_{w}\right)=$ dimensionless coefficient obtained for values of $T_{w}$ by interpolation from a table given by Goff [5].

$\beta\left(T_{w}\right)=$ dimensionless coefficient obtained for values of $T_{w}$ by interpolation from a table given by Goff [5].

$P=$ Total pressure at the psychrometer outlet in atmospheres.

$e_{w}=$ saturation vapor pressure in atmospheres, obtained by solving equation given by Goff [5].

$\Delta T=T_{D}-T_{W}{ }^{\circ} \mathrm{C}$.

The results of the calibration are given in table 1 and indicate that there is a mean difference in mixing ratio $r$ of $+0.047 \mathrm{~g} / \mathrm{kg}$ between the generator and this instrument. The largest difference measured is $0.119 \mathrm{~g} / \mathrm{kg}$.

The results are also given in terms of the partial pressure of vapor and dew-point that would exist in air of the same mixing ratio at ambient pressure [4].

It was found that the differences were well represented by a linear relationship with respect to the instrument indications, but that points 4,6 , and 40 deviated from this curve by an amount greater than that which should be expected in 52 measurements (standardized residual ${ }^{2}$ greater than 2.34). We therefore, eliminated points 4,6 , and 40 on the basis that they were not statistically representative of the calibration and refitted the remaining 49 points to a linear equation, which we shall consider an error curve: Error $=0.025+0.24$ percent of indication in grams of water per kilogram of dry air.

2 The standardized residual is the deviation of the point from the fitted curve divided by its own standard deviation.
The estimate of the standard deviation of this error is $0.024 \mathrm{~g} / \mathrm{kg}$.

\section{Error Analysis}

As was mentioned above, one of the purposes of the calibration of this instrument was to determine whether this instrument performed as an adiabatic saturation instrument. We propose to accomplish this by comparing the differences between the pressure humidity generator and this instrument with the uncertainties associated with these two instruments. Whereas assignment of random uncertainties can often be done with reasonable accuracy by statistical analysis, assignments of systematic uncertainties are usually more subjective and arbitrary. The most we can hope to come up with are reasonable estimates of these systematic uncertainties.

We estimate the maximum systematic uncertainty in our ambient pressure measurement to be $0.1 \mathrm{~mm} \mathrm{Hg}$ and the maximum systematic uncertainty in our pressure difference measurements to be 0.2 in of water. For our temperature measurements we have taken three residual standard deviations of our fitted curve and have added to these $0.002{ }^{\circ} \mathrm{C}$, our estimate of the systematic uncertainty in our resistance thermometer temperature measurement. This amounts to $0.031{ }^{\circ} \mathrm{C}$ for our entrance temperature measurement and $0.023{ }^{\circ} \mathrm{C}$ for our exit temperature measurement. Our final estimate of systematic uncertainty is for our pressure humidity generator [3] which we estimate to be 0.05 percent of indication.

We have likewise assigned random uncertainties to the same parameters as follows: $0.05 \mathrm{~mm} \mathrm{Hg}$. in ambient pressure, 0.2 in of water in pressure difference, $0.010{ }^{\circ} \mathrm{C}$ in inlet temperature, $0.007{ }^{\circ} \mathrm{C}$ in outlet temperature and 0.1 percent of indication for the pressure humidity generator. The random uncertainties assigned to the temperatures are the estimates of one residual standard deviation for the temperature equation used.

In order to determine the maximum total systematic uncertainty to be expected from the psychrometer at each calibration point, we reevaluated eq (5) for each of the calibration points with each parameter changed by the amount of the systematic uncertainty for that parameter and assigned signs to these uncertainties such that they would maximize the difference. In order to determine the random uncertainty of the instrument, we changed one parameter at a time by an amount equal to the estimate of the random uncertainty in that parameter and calculated the difference in mixing ratio this would cause by means of eq (5). We applied the propagation of error formula [8] at each calibration point to obtain an estimate of the one sigma random uncertainty. For the pressure humidity generator, we applied the pertinent estimated percentage uncertainties to the indicated value of mixing ratio. We added the two estimated systematic uncertainties together to obtain an overall estimate of the predicted maximum systematic difference between the two instruments and the root mean square of the two random uncertainties was used as the estimate of the predicted one sigma random difference to be expected. Table 2 gives these values along with the measured mixing ratio and the measured difference.

As was mentioned in the calibration section, the mea- 
TABLE 1. Calibration results

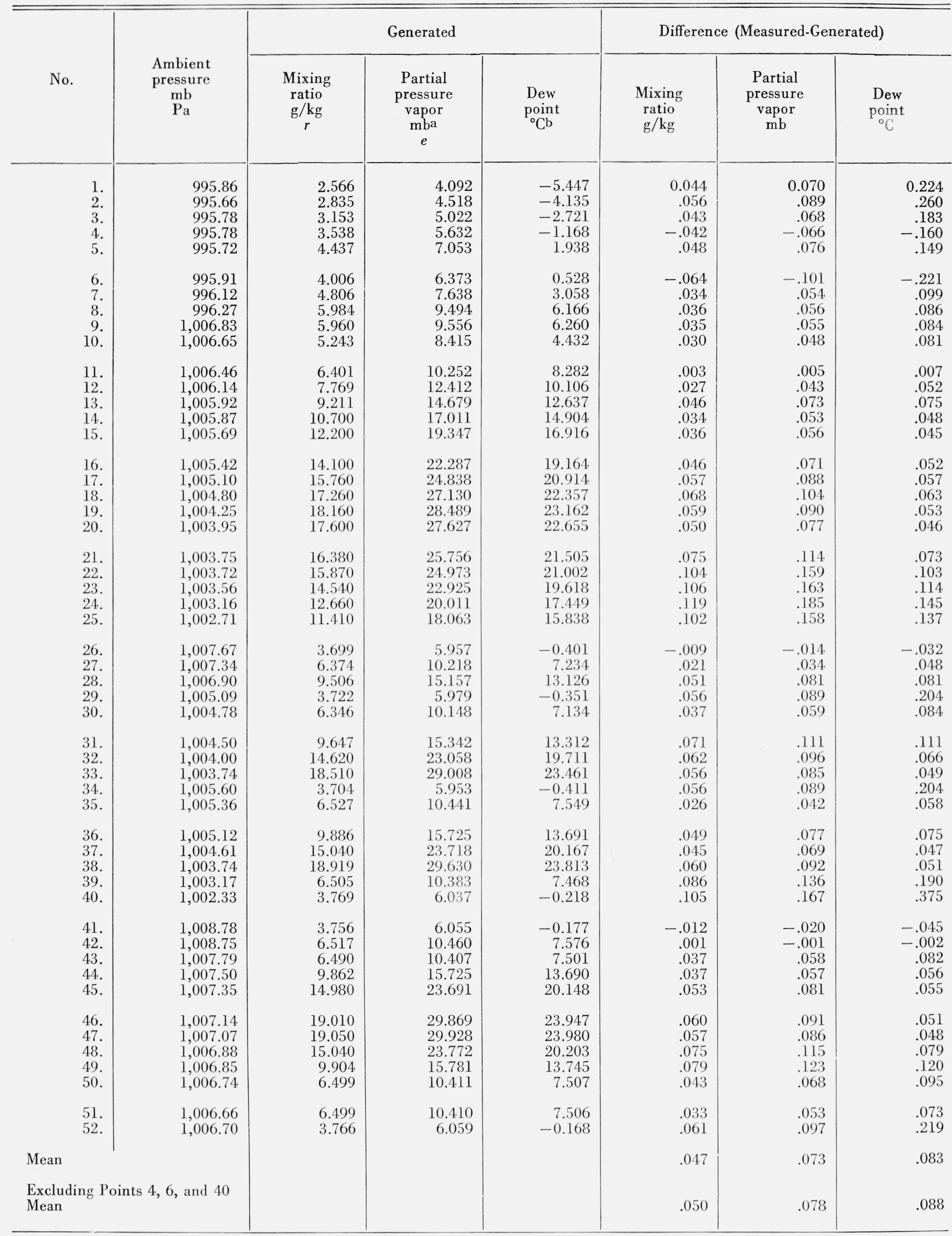

$\mathrm{a} e=\frac{r \mathrm{~Pa}}{0.62198+r}$ with respect to ambient pressure ( $r$ in grams per gram) [4].

bThe temperature at which the saturation mixing ratio at ambient pressure equals the generated mixing ratio. 
TABLE 2. Error analysis

\begin{tabular}{|c|c|c|c|c|c|c|c|c|}
\hline \multirow[b]{2}{*}{ No. } & \multirow{2}{*}{$\begin{array}{c}\text { Measured } \\
\text { mixing ratio } \\
\mathrm{g} / \mathrm{kg}\end{array}$} & \multirow{2}{*}{$\begin{array}{c}\text { Measured } \\
\text { difference } \\
\text { psychrometer- } \\
\text { generator } \\
\mathrm{g} / \mathrm{kg}\end{array}$} & \multicolumn{2}{|c|}{ Estimated systematic error } & \multicolumn{2}{|c|}{ Estimated random error } & \multicolumn{2}{|c|}{ Estimated differences } \\
\hline & & & $\begin{array}{c}\text { Psychrometera } \\
\mathrm{g} / \mathrm{kg}\end{array}$ & $\begin{array}{l}\text { Generator } \\
\mathrm{g} / \mathrm{kg}\end{array}$ & $\begin{array}{c}\text { Psychrometera } \\
\mathrm{g} / \mathrm{kg}\end{array}$ & $\begin{array}{l}\text { Generator } \\
\mathrm{g} / \mathrm{kg}\end{array}$ & $\begin{array}{l}\text { Systematic } \\
\mathrm{g} / \mathrm{kg}\end{array}$ & $\underset{\mathrm{g} / \mathrm{kg}}{\text { Random }}$ \\
\hline $\begin{array}{l}1 . \\
2 . \\
3 . \\
4 . \\
5 .\end{array}$ & $\begin{array}{l}2.610 \\
2.891 \\
3.196 \\
3.496 \\
4.485\end{array}$ & $\begin{array}{r}0.044 \\
.056 \\
.043 \\
-.042 \\
.048\end{array}$ & $\begin{array}{l}0.048 \\
.049 \\
.049 \\
.050 \\
.051\end{array}$ & $\begin{array}{l}0.001 \\
.001 \\
.002 \\
.002 \\
.002\end{array}$ & $\begin{array}{r}0.011 \\
.012 \\
.012 \\
.012 \\
.012\end{array}$ & $\begin{array}{l}0.003 \\
.003 \\
.003 \\
.003 \\
.004\end{array}$ & $\begin{array}{l}0.049 \\
.050 \\
.051 \\
.052 \\
.053\end{array}$ & $\begin{array}{r}0.011 \\
.012 \\
.012 \\
.012 \\
.013\end{array}$ \\
\hline $\begin{array}{r}6 . \\
7 . \\
8 . \\
9 . \\
10 .\end{array}$ & $\begin{array}{l}3.942 \\
4.840 \\
6.020 \\
5.995 \\
5.273\end{array}$ & $\begin{array}{r}-.064 \\
.034 \\
.036 \\
.035 \\
.030\end{array}$ & $\begin{array}{l}.050 \\
.052 \\
.054 \\
.053 \\
.052\end{array}$ & $\begin{array}{l}.002 \\
.002 \\
.003 \\
.003 \\
.003\end{array}$ & $\begin{array}{l}.012 \\
.012 \\
.013 \\
.013 \\
.012\end{array}$ & $\begin{array}{l}.004 \\
.005 \\
.006 \\
.006 \\
.005\end{array}$ & $\begin{array}{l}.052 \\
.054 \\
.057 \\
.056 \\
.055\end{array}$ & $\begin{array}{l}.013 \\
.013 \\
.014 \\
.014 \\
.013\end{array}$ \\
\hline $\begin{array}{l}11 . \\
12 . \\
13 . \\
14 . \\
15 .\end{array}$ & $\begin{array}{r}6.404 \\
7.796 \\
9.257 \\
10.734 \\
12.236\end{array}$ & $\begin{array}{l}.003 \\
.027 \\
.046 \\
.034 \\
.036\end{array}$ & $\begin{array}{l}.054 \\
.056 \\
.058 \\
.061 \\
.063\end{array}$ & $\begin{array}{l}.003 \\
.004 \\
.005 \\
.005 \\
.006\end{array}$ & $\begin{array}{l}.013 \\
.014 \\
.014 \\
.015 \\
.016\end{array}$ & $\begin{array}{l}.006 \\
.008 \\
.009 \\
.011 \\
.012\end{array}$ & $\begin{array}{l}.057 \\
.060 \\
.063 \\
.066 \\
.069\end{array}$ & $\begin{array}{l}.014 \\
.016 \\
.017 \\
.019 \\
.020\end{array}$ \\
\hline $\begin{array}{l}16 . \\
17 . \\
18 . \\
19 . \\
20 .\end{array}$ & $\begin{array}{l}14.146 \\
15.817 \\
17.328 \\
18.219 \\
17.650\end{array}$ & $\begin{array}{l}.046 \\
.057 \\
.068 \\
.059 \\
.050\end{array}$ & $\begin{array}{l}.066 \\
.069 \\
.071 \\
.073 \\
.072\end{array}$ & $\begin{array}{l}.007 \\
.008 \\
.009 \\
.009 \\
.009\end{array}$ & $\begin{array}{l}.017 \\
.018 \\
.019 \\
.019 \\
.019\end{array}$ & $\begin{array}{l}.014 \\
.016 \\
.017 \\
.018 \\
.018\end{array}$ & $\begin{array}{l}.073 \\
.077 \\
.080 \\
.082 \\
.081\end{array}$ & $\begin{array}{l}.022 \\
.024 \\
.025 \\
.027 \\
.027\end{array}$ \\
\hline $\begin{array}{l}21 . \\
22 . \\
23 . \\
24 . \\
25 .\end{array}$ & $\begin{array}{l}16.455 \\
15.974 \\
14.646 \\
12.779 \\
11.512\end{array}$ & $\begin{array}{l}.075 \\
.104 \\
.106 \\
.119 \\
.102\end{array}$ & $\begin{array}{l}.070 \\
.069 \\
.067 \\
.064 \\
.062\end{array}$ & $\begin{array}{l}.008 \\
.008 \\
.007 \\
.006 \\
.006\end{array}$ & $\begin{array}{l}.018 \\
.018 \\
.017 \\
.016 \\
.016\end{array}$ & $\begin{array}{l}.016 \\
.016 \\
.015 \\
.013 \\
.012\end{array}$ & $\begin{array}{l}.078 \\
.077 \\
.073 \\
.070 \\
.068\end{array}$ & $\begin{array}{l}.024 \\
.024 \\
.023 \\
.021 \\
.020\end{array}$ \\
\hline $\begin{array}{l}26 . \\
27 . \\
28 . \\
29 . \\
30 .\end{array}$ & $\begin{array}{l}3.690 \\
6.395 \\
4.557 \\
3.778 \\
6.383\end{array}$ & $\begin{array}{r}-.009 \\
.021 \\
.051 \\
.056 \\
.037\end{array}$ & $\begin{array}{l}.050 \\
.054 \\
.059 \\
.050 \\
.054\end{array}$ & $\begin{array}{l}.002 \\
.003 \\
.005 \\
.002 \\
.003\end{array}$ & $\begin{array}{l}.012 \\
.013 \\
.015 \\
.012 \\
.013\end{array}$ & $\begin{array}{l}.004 \\
.006 \\
.010 \\
.004 \\
.006\end{array}$ & $\begin{array}{l}.052 \\
.057 \\
.064 \\
.052 \\
.057\end{array}$ & $\begin{array}{l}.013 \\
.014 \\
.018 \\
.013 \\
.014\end{array}$ \\
\hline $\begin{array}{l}31 . \\
32 . \\
33 . \\
34 . \\
35 .\end{array}$ & $\begin{array}{r}9.718 \\
14.682 \\
18.566 \\
3.760 \\
6.553\end{array}$ & $\begin{array}{l}.071 \\
.062 \\
.056 \\
.056 \\
.026\end{array}$ & $\begin{array}{l}.059 \\
.067 \\
.074 \\
.050 \\
.054\end{array}$ & $\begin{array}{l}.005 \\
.007 \\
.009 \\
.002 \\
.003\end{array}$ & $\begin{array}{l}.015 \\
.017 \\
.019 \\
.012 \\
.013\end{array}$ & $\begin{array}{l}.010 \\
.015 \\
.019 \\
.004 \\
.007\end{array}$ & $\begin{array}{l}.064 \\
.074 \\
.083 \\
.052 \\
.057\end{array}$ & $\begin{array}{l}.018 \\
.023 \\
.027 \\
.013 \\
.015\end{array}$ \\
\hline $\begin{array}{l}36 . \\
37 . \\
38 . \\
39 . \\
40 .\end{array}$ & $\begin{array}{r}9.935 \\
15.085 \\
18.979 \\
6.591 \\
3.874\end{array}$ & $\begin{array}{l}.049 \\
.045 \\
.060 \\
.086 \\
.105\end{array}$ & $\begin{array}{l}.059 \\
.067 \\
.074 \\
.055 \\
.051\end{array}$ & $\begin{array}{l}.005 \\
.008 \\
.009 \\
.003 \\
.002\end{array}$ & $\begin{array}{l}.015 \\
.017 \\
.019 \\
.013 \\
.012\end{array}$ & $\begin{array}{l}.010 \\
.015 \\
.019 \\
.007 \\
.004\end{array}$ & $\begin{array}{l}.064 \\
.075 \\
.083 \\
.058 \\
.053\end{array}$ & $\begin{array}{l}.018 \\
.023 \\
.027 \\
.015 \\
.013\end{array}$ \\
\hline $\begin{array}{l}41 . \\
42 . \\
43 . \\
44 . \\
45 .\end{array}$ & $\begin{array}{r}3.744 \\
6.516 \\
6.527 \\
9.899 \\
15.033\end{array}$ & $\begin{array}{r}-.012 \\
-.001 \\
.037 \\
.037 \\
.053\end{array}$ & $\begin{array}{l}.050 \\
.054 \\
.054 \\
.060 \\
.068\end{array}$ & $\begin{array}{l}.002 \\
.003 \\
.003 \\
.005 \\
.008\end{array}$ & $\begin{array}{l}.012 \\
.013 \\
.013 \\
.015 \\
.017\end{array}$ & $\begin{array}{l}.004 \\
.007 \\
.007 \\
.010 \\
.015\end{array}$ & $\begin{array}{l}.052 \\
.057 \\
.057 \\
.065 \\
.076\end{array}$ & $\begin{array}{l}.013 \\
.015 \\
.015 \\
.018 \\
.023\end{array}$ \\
\hline $\begin{array}{l}46 . \\
47 . \\
48 . \\
49 . \\
50 .\end{array}$ & $\begin{array}{r}19.070 \\
19.107 \\
15.115 \\
9.983 \\
6.542\end{array}$ & $\begin{array}{l}.060 \\
.057 \\
.075 \\
.079 \\
.043\end{array}$ & $\begin{array}{l}.074 \\
.075 \\
.068 \\
.060 \\
.055\end{array}$ & $\begin{array}{l}.010 \\
.010 \\
.008 \\
.005 \\
.003\end{array}$ & $\begin{array}{l}.019 \\
.020 \\
.017 \\
.015 \\
.013\end{array}$ & $\begin{array}{l}.019 \\
.019 \\
.015 \\
.010 \\
.007\end{array}$ & $\begin{array}{l}.084 \\
.085 \\
.076 \\
.065 \\
.058\end{array}$ & $\begin{array}{l}.027 \\
.028 \\
.023 \\
.018 \\
.015\end{array}$ \\
\hline $\begin{array}{l}51 . \\
52 .\end{array}$ & $\begin{array}{l}6.532 \\
3.827\end{array}$ & $\begin{array}{l}.033 \\
.061\end{array}$ & $\begin{array}{l}.055 \\
.051\end{array}$ & $\begin{array}{l}.003 \\
.002\end{array}$ & $\begin{array}{l}.013 \\
.012\end{array}$ & $\begin{array}{l}.007 \\
.004\end{array}$ & $\begin{array}{l}.058 \\
.053\end{array}$ & $\begin{array}{l}.015 \\
.013\end{array}$ \\
\hline
\end{tabular}

aCalculated by means of eq. (5) as described in section 5 .

sured differences were fitted by least squares methods to a linear curve in terms of measured mixing ratio.

The result is

$$
\Delta r_{\text {meas }}=0.025+0.0024 r
$$

(a) standard deviation of this fit is 0.024 .

where $\Delta r_{\text {meas }}$ is the measured difference in mixing ratio between the generator and this instrument and $r$ is the mixing ratio measured by this instrument. The residual 
The estimated systematic difference was similarly fitted to a linear equation and the result is

$$
\Delta r_{\mathrm{est}}=0.044+0.0021 r
$$

where $\Delta r_{\text {est }}$ is the estimated maximum systematic difference and $r$ is the measured mixing ratio. The root mean square of the estimated random errors is 0.019. The smoothed measured systematic difference is less than the smoothed estimate of the maximum systematic difference expected. The random component of the measured differences exceeds the estimate of the random difference by about 26 percent.

The results were further analyzed by comparing the difference between the measured exit temperature of the psychrometer and that exit temperature necessary to obtain values identical with the generator, all other measurements remaining as measured. The results are shown in table 3 along with the estimated total systematic uncertainty computed in terms of exit temperature and the estimated random uncertainty computed in similar terms.

The measured difference in terms of exit temperature is essentially a constant and the mean value is $0.032{ }^{\circ} \mathrm{C}$ with a residual standard deviation of $0.017^{\circ} \mathrm{C}$. Except for a slight slope due to the fact that the estimates of the uncertainties in the generator are linearly dependent on the generated value of the mixing ratio, the estimated systematic uncertainty is essentially constant at $0.042{ }^{\circ} \mathrm{C}$ and the estimate of random uncertainty is also nearly constant with a root mean square value of $0.012{ }^{\circ} \mathrm{C}$.

In terms of exit temperature, the measured difference and the estimated total uncertainty are both essentially a constant with the estimated value exceeding the measured value. The residual standard deviation of the measured value exceeds the estimated random uncertainty by about 42 percent.

The results indicate that the instrument performs in general within the limits that would be expected on the basis of eq (5).

The time constant of the instrument was measured and found to be approximately $3 \mathrm{~min}$ from the dry-to-wet condition and slightly less in the wet-to-dry condition. This can have an effect on the instrument indication.

Calibration points 9 through 25 were performed sequentially, some as closely spaced as $11 \mathrm{~min}$ apart. Part of the time between successive points was used in changing and stabilizing the humidity generator. Therefore, the actual time provided for the psychrometer to come to equilibrium was less than the time between points.

Due to the short time allowed for a stable reading, the measured mixing ratio for points 11 through 15 are probably somewhat lower than they would be at complete equilibrium. Likewise, points 21 through 24 are probably somewhat higher than they would have been had complete equilibrium been achieved. Adequate data are not available for a quantitative evaluation of this nonequilibrium effect but the direction is consistent with the change in generated humidity and, due to its dual nature, should have small effect on the overall calibration results.

The inlet temperature had a variation of $1 \frac{1 / 2}{2}$ degrees throughout the entire calibration. Though this in itself is of no great importance, the rate at which it changed is. The maximum rate of change detected was $0.026{ }^{\circ} \mathrm{C}$ per minute. A difference of $0.026{ }^{\circ} \mathrm{C}$ in inlet temperature
TABLE 3. Error analysis

(All errors assigned as exit temperature errors)

\begin{tabular}{|c|c|c|c|c|}
\hline No. & $\begin{array}{l}\text { Measured } \\
\text { exit temp. } \\
{ }^{\circ} \mathrm{C}\end{array}$ & $\begin{array}{c}\text { Exit tempa } \\
\text { difference } \\
{ }^{\circ} \mathrm{C}\end{array}$ & $\begin{array}{c}\text { Estimated b } \\
\text { systematic } \\
\text { difference } \\
{ }^{\circ} \mathrm{C}\end{array}$ & $\begin{array}{c}\text { Estimated b } \\
\text { random } \\
\text { difference } \\
{ }^{\circ} \mathrm{C}\end{array}$ \\
\hline 1. & 16.799 & 0.036 & 0.040 & 0.010 \\
\hline 2. & 17.026 & .046 & .041 & .010 \\
\hline 3. & 17.298 & .035 & .042 & .009 \\
\hline 4. & 17.540 & -.034 & .043 & .009 \\
\hline 5. & 18.321 & .023 & .042 & .010 \\
\hline 6. & 17.885 & -.051 & .041 & .010 \\
\hline 7. & 18.607 & .026 & .041 & .010 \\
\hline 8. & 19.542 & .027 & .042 & .011 \\
\hline 9. & 19.538 & .026 & .042 & .011 \\
\hline 10. & 18.966 & .023 & .042 & .010 \\
\hline 11. & 19.848 & .002 & .042 & .011 \\
\hline 12. & 20.877 & .019 & .042 & .011 \\
\hline 13. & 21.894 & .031 & .043 & .012 \\
\hline 14. & 22.886 & .022 & .042 & .013 \\
\hline 15. & 23.866 & .022 & .043 & .013 \\
\hline 16. & 25.064 & .027 & .043 & .013 \\
\hline 17. & 26.040 & .032 & .043 & .014 \\
\hline 18. & 26.904 & .036 & .043 & .013 \\
\hline 19. & 27.406 & .032 & .044 & .015 \\
\hline 20. & 27.102 & .027 & .043 & .015 \\
\hline 21. & 26.460 & .041 & .043 & .013 \\
\hline 22. & 26.198 & .058 & .043 & .013 \\
\hline 23. & 25.445 & .061 & .042 & .013 \\
\hline 24. & 24.332 & .072 & .042 & .012 \\
\hline 25. & 23.530 & .063 & .042 & .013 \\
\hline 26. & 17.846 & -.007 & .041 & .010 \\
\hline 27. & 19.922 & .016 & .042 & .010 \\
\hline 28. & 22.118 & .034 & .043 & .013 \\
\hline 29. & 17.896 & .044 & .043 & .010 \\
\hline 30. & 19.969 & .027 & .042 & .010 \\
\hline 31. & 22.283 & .047 & .041 & .011 \\
\hline 32. & 25.392 & .036 & .043 & .013 \\
\hline 33. & 27.584 & .029 & .043 & .015 \\
\hline 34. & 17.759 & .044 & .041 & .010 \\
\hline 35. & 19.958 & .019 & .042 & .010 \\
\hline 36. & 22.302 & .032 & .042 & .011 \\
\hline 37. & 25.549 & .026 & .043 & .013 \\
\hline 38. & 27.807 & .031 & .043 & .015 \\
\hline 39. & 20.258 & .062 & .042 & .010 \\
\hline 40. & 18.152 & .083 & .042 & .010 \\
\hline 41. & 17.856 & -.010 & .041 & .010 \\
\hline 42. & 20.052 & -.001 & .042 & .010 \\
\hline 43. & 20.154 & .027 & .041 & .010 \\
\hline 44. & 22.519 & .024 & .043 & .011 \\
\hline 45. & 25.713 & .030 & .044 & .013 \\
\hline 46. & 27.950 & .031 & .044 & .013 \\
\hline 47. & 27.997 & .029 & .043 & .014 \\
\hline 48. & 25.862 & .043 & .044 & .013 \\
\hline 49. & 22.725 & .052 & .043 & .011 \\
\hline 50. & 20.326 & .031 & .042 & .010 \\
\hline 51. & 20.303 & .024 & .042 & .010 \\
\hline 52. & 18.202 & .048 & .042 & .010 \\
\hline \multirow{2}{*}{\multicolumn{2}{|c|}{$\begin{array}{l}\text { Mean } \\
\text { Standard deviation }\end{array}$}} & 0.030 & 0.042 & 0.011 \\
\hline & & .023 & & \\
\hline \multicolumn{3}{|c|}{ Excluding Points 4,6 , and 40} & \multirow{3}{*}{0.042} & \multirow{3}{*}{0.012} \\
\hline \multirow{2}{*}{\multicolumn{2}{|c|}{$\begin{array}{l}\text { Mean } \\
\text { Standard deviation }\end{array}$}} & 0.032 & & \\
\hline & & .017 & & \\
\hline
\end{tabular}

a Measured exit temperature less the exit temperature that would give the generated mixing ratio values.

b Calculated by means of eq. (5) as described in section 5 . 
is equivalent to approximately $0.014 \mathrm{mg} / \mathrm{g}$ mixing ratio indication in the instrument. If the inlet temperature changed continuously at a rate of $0.026{ }^{\circ} \mathrm{C}$ per minute monotonically over a long period of time, an error in instrument indication would result amounting about 0.04 . $\mathrm{mg}$ per gram in mixing ratio. Examination of the calibration data indicates that the usual rate of change was much smaller and did not generally persist in one direction for long periods. This is not believed to have caused large errors. The standard deviation is probably larger due to this effect than would have been the case with constant inlet temperature, especially since all readings could not be taken simultaneously.

Examination of the calibration data further indicates some correlation between the inlet temperature and the temperature difference. This may have been due to conduction along the inlet thermistor giving an inlet temperature reading lower than the true inlet temperature. This would have the effect of causing larger values in measured $r$, and thereby could account for some of the error found in calibration. This effect is such that it would be more pronounced at lower values of $r$.

\section{Summary and Conclusion}

A heated-air adiabatic saturation psychrometer has been built that measures the mixing ratio of water from 0 to $50 \mathrm{~g} / \mathrm{kg}$. If three of the 52 calibration points are excluded as being statistically unrepresentative, the mean difference between the measured value and the generated value in the calibration over the range of 2.5 to $19 \mathrm{~g} / \mathrm{kg}$ was 0.050 . In terms of partial pressure of vapor the mean difference was 0.078 mbar and in terms of dewpoint temperature the mean difference was $0.088{ }^{\circ} \mathrm{C}$.

Analysis of the calibration results indicates that the instrument performs as an adiabatic instrument within the estimated uncertainty in the measured parameters of both the instrument and the humidity generator used in the calibration process. We conclude that the adiabatic saturation theory applies to this instrument at nonzero values of humidity, as well as at zero values.

Heating the inlet air broadens the mixing ratio range over which this instrument can be used and increases the ambient temperature range over which it can successfully operate but reduces the accuracy of the instrument at low values of humidity. It is therefore apparent that this type of instrument would find greater value in the measurement of high values of humidity. Increased accuracy is obtainable over the entire humidity range by increased accuracy and precision in the determination of exit temperature first, the entrance temperature next and the pressure last.

Were the entrance temperature to be better controlled, one would expect the random uncertainty to be decreased and the ease of taking measurements improved. Control of the entrance temperature to at least $0.1 \mathrm{deg} \mathrm{C}$ would make entrance temperature readings unnecessary for determination where the uncertainty in the humidity can be as large as $0.05 \mathrm{~g} / \mathrm{kg}$.

Where the instrument is to be operated at mixing ratios which will never exceed $20 \mathrm{~g} / \mathrm{kg}$, one could control the entrance temperature at $25{ }^{\circ} \mathrm{C}$ and obtain greater accuracy than with the $41{ }^{\circ} \mathrm{C}$ now used in the instrument.

\section{References}

[1] Greenspan, L., and Wexler, A. An Adiabatic Saturation Psychrometer. J. Res. Nat. Bur. Stand. (U.S.), 72C (Eng. \& Instr.) No. 1, 33-47 (Jan.-Mar. 1968).

[2] Wexler, A., Humidity Standards, Tappi 44, 180A, (June 1961).

[3] Wexler, A. Calibration of Humidity Measuring Instruments at the National Bureau of Standards, Analysis Instrumentation 6, 161 (Plenum Press, 1969).

[4] Smithsonian Meteorological Tables, Smithsonian Institution, Washington, D. C. (1951).

[5] Goff, J. A., and Gratch, S., Thermal properties of moist air, ASHVE Journal Section, Heating, Piping and Air Conditioning 51, 334 (June 1945).

[6] Harrison, L. P., Fundamental Concepts and Definitions Relating to Humidity, Humidity and Moisture 3, 49 (Reinhold Publishing Corp., New York 1965).

[7] Goff, J. A., Saturation Pressure of Water on the New Kelvin Scale, Humidity and Moisture 3, 289 (Reinhold Publishing Corp., New York 1965).

[8] Ku, H. H., Notes on the Use of Propagation of Error Formulas. J. Res. Nat. Bur. Stand. (U.S.), 70C (Eng. \& Instr.) No. 4, 263-273 (Oct.-Dec. 1966).

(Paper 75C2-314) 